\title{
PERAN UNITED NATIONS DEVELOPMENT \\ PROGRAMME \\ INDONESIA \\ DALAM \\ MENGIMPLEMENTASIKAN DIFUSI INOVASI AGENDA SUSTAINABLE DEVELOPMENT GOALS UNTUK MEMBANGUN KESADARAN PEMUDA MENGENAI MASALAH SAMPAH PLASTIK
}

Joe Harrianto Setiawan ${ }^{1}$, Cintia Caroline ${ }^{2}$

${ }^{1,2}$ Institut Komunikasi dan Bisnis London School of Public Relations

Email: cintiacarolinee@yahoo.com (korespondensi)

\begin{abstract}
The United Nations Development Program (UNDP) in Indonesia carrying out the mandate contained in the global development agenda / Sustainable Development Goals (SDG). Longterm development in Indonesia is threatened by environmental degradation and climate change shown by the status as one of the biggest producers of greenhouse gas emissions and plastic waste in the world. SDG is a diffusion of innovation activity is targeting the role of youth in its process towards sustainable development. By using the main theory Diffusion of Innovation and with descriptive qualitative research methods, the result has shown that the diffusion of innovation UNDP is not so complicated, but still has difficulty in including the agent of change, therefore it needs a direct approach that is friendly and easy for the youth to understand. UNDP Indonesia diffuses the innovations through internet and events/programs through the contribution of the agent of change.
\end{abstract}

Keywords: Diffusion of innovation, International organization, plastic waste, sustainable development

United Nations Development Programme (UNDP) berada di Indonesia menjalankan mandat yang tertuang dalam agenda pembangunan global / Sustainable Development Goals (SDG). Pembangunan jangka panjang di Indonesia yang terancam oleh degradasi lingkungan dan perubahan iklim, ditunjukkan dengan status sebagai salah satu penghasil emisi gas rumah kaca dan sampah plastik terbesar di dunia. SDG yang merupakan bentuk kegiatan difusi inovasi menargetkan peranan pemuda dalam proses menuju pembangunan yang berkelanjutan. Dengan teori utama Difusi Inovasi dan metode penelitian kualitatif deskriptif, hasil penelitian menunjukkan bahwa difusi inovasi UNDP Indonesia tidak begitu rumit, namun masih ditemukan kesulitan dalam menyertakan agen perubahan sehingga perlu pendekatan langsung yang ramah dan mudah dipahami pemuda. UNDP Indonesia melakukan difusi inovasi melalui internet dan event/program dengan bantuan agen perubahan.

Kata kunci: Difusi inovasi, organisasi internasional, pembangunan berkelanjutan, sampah plastik

\section{PENDAHUlUAN}

Setiap negara memiliki permasalahan ekonomi, sosial, politik, dan sebagainya terutama dalam negara berkembang. Dengan menganut sistem politik luar negeri bebas aktif, Indonesia memiliki keleluasaan untuk menjalankan dan memperjuangkan kepentingan nasional dengan mengacu pada prinsip untuk berkontribusi aktif dalam menjaga perdamaian dunia. Upaya
Indonesia ini diwujudkan dalam keanggotaannya dalam sebuah badan dunia, yaitu Perserikatan Bangsa Bangsa / PBB (Pramudyani, 2019).

Sebagai anggota PBB, Indonesia pun terdaftar dalam beberapa lembaga di bawah naungan PBB, salah satunya adalah UNDP (United Nations Development Programme), yaitu jaringan pembangunan global PBB yang mengadvokasi perubahan dan 
menghubungkan negara-negara dengan pengetahuan, pengalaman dan sumber daya untuk membantu masyarakat negara tersebut membangun kehidupannya yang lebih baik (UNDP Indonesia, n.d.-a).

Mandat UNDP tertuang dalam agenda Tujuan Pembangunan Berkelanjutan (TPB) atau Sustainable Development Goals (SDGs). Sustainable Development Goals merupakan agenda pembangunan universal dalam dokumen Transforming Our World: the 2030 Agenda for Sustainable Development yang disepakati pada 25 September 2015 saat Sidang Umum PBB ketujuh puluh. Agenda SDG berisi tujuh belas Tujuan (Goals) dan seratus enam puluh sembilan sasaran yang berlaku mulai 2016 hingga 2030 (Fitri, 2016).

UNDP (United Nations Development Programme) mengimplementasikan SDG dengan berfokus pada sistem, penyebab, dan hal-hal yang terkait dengan masalah yang dihadapi negara (UNDP Asia Pacific, 2019c). Komitmen Indonesia dalam pelaksanaan pencapaian SDG terdapat dalam Peraturan Presiden (Perpres) nomor 59 tahun 2017 agar dilaksanakan secara partisipatif dengan melibatkan seluruh pihak (SDG 2030 Indonesia, n.d.).

Tantangan bagi Indonesia adalah bagaimana menghasilkan pertumbuhan negara, yaitu mengurangi kemiskinan dan kesenjangan, dan pada saat yang sama tetap menjaga dan melindungi sumber daya alam serta prospek pembangunan jangka Panjang (United Nations Development Programme Indonesia, n.d). Pembangunan jangka panjang di Indonesia terancam oleh degradasi lingkungan dan perubahan iklim. Pertumbuhan ekonomi Indonesia sebagian besar didorong oleh ekstraksi sumber daya alam dengan mengorbankan lingkungan. Indonesia juga merupakan salah satu penghasil emisi gas rumah kaca terbesar dunia (UNDP Indonesia, n.d. -b).

Studi oleh McKinsey and Co dan Ocean Conservancy dalam artikel berjudul "Wow, Indonesia Produksi 64 Juta Ton Sampah per Tahun" juga menyebutkan Indonesia adalah penghasil sampah plastik nomor dua di dunia setelah Tiongkok dengan. data dari Kementerian Lingkungan Hidup dan Kehutanan (KLHK), rata-rata produksi sampah 175.000 ton per hari atau 64 juta ton per tahun (Fatah, 2019).

Plastik terbuat dari minyak bumi yang diubah menjadi molekul kecil atau monomer melalui proses pembakaran. Sampah plastik juga tidak dapat terurai secara alami oleh bakteri dalam tanah, sehingga biasanya pengelolaan sampah plastik dilakukan melalui pembakaran. Proses produksi hingga pembuangan dan pengelolaan sampah plastik ini menghasilkan emisi gas rumah kaca di atmosfer bumi (Direktorat Jenderal Pengendalian Perubahan Iklim, 2017).
Masalah sampah plastik dalam agenda SDGs terpusat pada tujuan atau goal ke-dua belas mengenai konsumsi dan produksi yang bertanggung jawab, dan goal ke-tiga belas mengenai penanganan perubahan iklim. Goals lainnya pun akan terpengaruh dan mempengaruhi barik secara langsung maupun tidak.

Upaya implementasi agenda SDG yang berkaitan dengan masalah sampah plastik adalah bentuk kegiatan difusi inovasi atau penyebaran ide baru yang dikembangkan oleh Everett $M$ Roger melalui bukunya Difussion of Innovation (1983) sebagai suatu proses dimana inovasi dikomunikasikan melalui saluran-saluran tertentu dalam rentang waktu tertentu di dalam suatu keompok masyarakat. Inovasi UNDP Indonesia dalam mengimplementasikan agenda SDG yang berlaku sejak 2016 hingga 2030 mengenai masalah sampah plastik dikomunikasikan melalui saluran-saluran tertentu, inilah yang disebut difusi dalam penelitian ini. Menurut Incognito (2015, p.84), dalam Inovasi pembangunan Indonesia, generasi muda dalam komponen masyarakat adalah yang selalu dituntut.

Perlunya peran pemuda dalam beberapa target dan indikator SDGs, serta agendanya yang mencakup komitmen merealisasikan hak dan kemampuan (anak muda), dapat membantu Indonesia mendapatkan dividen demografis. Harapan untuk membangun dunia yang lebih makmur, adil, inklusif, dan damai berada di pundak kaum muda, tidak terkecuali karena jumlah mereka yang banyak (Commonwealth Secretariat, 2016). Hasil survei Badan Pusat Statistik pada 2018 menunjukkan populasi pemuda Indonesia adalah 63,82 juta sama dengan seperempat $(24,15$ persen) dari total penduduk Indonesia. Artinya satu dari empat penduduk Indonesia adalah pemuda (Maylasari, Rachmawati, Agustina, Silviliyana, Dewi, Annisa, Lanny, Nugroho, 2018). Sejumlah kegiatan yang ditunjukkan ke pemuda telah diadakan oleh UNDP Indonesia, seperti Social Good Summit, SDGs Talk, dan Youth Co:Lab.

Berdasarkan uraian tersebut, masalah penelitian ini mengarah pada rumusan masalah mengenai bagaimana peran United Nations Development Programme Indonesia dalam mengimplementasikan difusi inovasi agenda Sustainable Development Goals untuk membangun kesadaran pemuda Indonesia mengenai permasalahan sampah plastik? Berdasarkan faktor-faktor yang mempengaruhi difusi inovasi, tujuan penelitian ini adalah untuk mengetahui atribut inovasi, jenis keputusan inovasi, saluran komunikasi, kondisi sistem sosial, dan peran agen perubahan dalam membangun kesadaran pemuda Indonesia mengenai permasalahan sampah plastik oleh UNDP Indonesia dalam mengimplementasikan agenda SDG. 


\section{TINJAUAN PUSTAKA}

\subsection{Organisasi Internasional}

Sebuah organisasi mempunyai tujuan untuk saling membentuk atau menerima satu sama lain antar anggota organisasi untuk mencapai suatu tujuan bersama atas dasar perasaan senasib dan sepenanggungan (Umbara, 2018, p.114). Peraturan Presiden (Perpres) Nomor 30 Tahun 2019 Bab I pasal 2 menyebutkan bahwa keanggotaan dan kontribusi Indonesia pada Organisasi Internasional bertujuan untuk peran dan kinerja Indonesia di forum Internasional, hubungan antara Pemerintah Republik Indonesia dengan pemerintah negara lain, dan kepercayaan masyarakat internasional (Direktorat Utama Pembinaan dan Pengembangan Hukum Pemeriksaan Keuangan Negara BPK RI, 2017a).

Organisasi terbesar negara-negara di dunia adalah Perserikatan Bangsa-Bangsa (PBB / UNO = United Nations Organization) atau UN (United Nations) yang didirikan pada 24 Oktober 1945. Anggota PBB meliputi hampir seluruh negara di dunia dan dibentuk untuk memfasilitasi hukum internasional, pengamanan internasional, lembaga ekonomi, dan perlindungan sosial di dunia (Komandoko, 2010, p.208).

Menurut Soedjatmoko, anggota delegasi PBB pada 1947-1952 (dalam Pusat Data dan Analisis Tempo, 2019, p.51) bahwa Indonesia diterima sebagai anggota PBB pada akhir 1950 saat Menteri Luar Negeri Moh. Roem menghadiri Sidang Majelis Umum sebagai ketua delegasi. Hal ini adalah salah satu tujuan perjuangan yang identik dengan pengakuan dunia.

Dengan demikian, badan dunia adalah hasil kesepakatan diantara pihak-pihak yang berwenang dari negara-negara yang berkomitmen untuk memajukan kualitas hidup masyarakat dan lingkungan didalam negara tersebut kearah yang lebih baik dengan membentuk sebuah kebersamaan atas dasar komitmen dan tujuan tertentu.

\subsection{Komunikasi Pembangunan}

Everett M. Rogers menyatakan bahwa pembangunan adalah perubahan menuju suatu sistem sosial dan ekonomi yang diputuskan sebagai kehendak suatu bangsa. Perubahan yang dikehendaki tentunya kearah yang lebih baik atau lebih maju (Oktarina \& Abdullah, 2017, p.128-129). Komunikasi pembangunan merupakan disiplin ilmu dan praktikum komunikasi dalam konteks negara-negara sedang berkembang, terutama kegiatan komunikasi untuk perubahan sosial yang direncanakan (Harun \& Ardianto, 2011, p.161).

Komunikasi pembangunan menjadi sistem informasi masyarakat mengenai pembangunan lingkungan dan masyarakat tersebut, memberikan kesempatan masyarakat untuk berperan aktif dalam membuat keputusan melalui dialog, serta diaplikasikan dalam mendidik tenaga kerja sebagai pengembangan wawasan berpikir dan pemberdayaan masyarakat secara menyeluruh (Riva'i, 2016, p.1). Komunikasi dan pembangunan sangatlah berkaitan, menurut Widjaja (1987), komunikasi dalam konteks pembangunan adalah "as an integral part of development and, communication as a set of variables instrumental in bringing about development" (dalam Oktarina dan Abdullah, 2017, p.128).

\subsection{Public Relations}

Praktik Public Relations menurut Sari (2017, p.5) adalah sebagai "jembatan" antara organisasi dengan publiknya dengan tujuan utama mencapai "mutual understanding".

Public Relations memiliki beberapa fungsi penting, yaitu mengabdi pada kepentingan umum, memelihara komunikasi yang baik, dan menitikberatkan moral dan tingkah laku. Faktor moral dalam fungsi Public Relations merupakan kegiatan komunikasi itu yang tidak hanya menyasar orang-orang didalam organisasi, tetapi juga di luar organisasi (Kriyantono, 2019, p.413).

Komunikasi tidak hanya soal pertukaran berita dan pesan, tetapi juga kegiatan individu dan kelompok untuk bertukar data, fakta, dan ide. Menurut Everett M. Rogers komunikasi adalah proses suatu ide dialihkan dari sumber kepada penerima untuk mengubah tingkah laku mereka (Ardial, 2018, p.9). Maka, salah satu fungsi komunikasi yang melekat dalam proses komunikasi adalah sosialisasi kemasyarakatan sebagai penyalur sumber ilmu pengetahuan yang memungkinkan orang bersikap dan bertindak sebagai anggota masyarakat secara efektif (Ardial, 2018, p.9).

Dengan demikian, Public Relations dalam penelitian ini adalah sebuah sistem komunikasi yang dimana proses pertukaran pesannya melalui sosialisasi kepada sekelompok masyarakat tertentu dengan tujuan menciptakan perubahan yang lebih baik.

\subsection{Teori Difusi Inovasi}

Penyebaran ide baru atau diffution of innovation adalah model komunikasi yang digunakan Everett M. Roger (1983) dalam proses pembangunan. Pembangunan yang dimaksud mengarah pada moderenisasi yang berusaha mengubah suatu negara atau suatu organisasi dengan sistem yang berasal dari luar (Kusumadinata, 2015 p.30-31). Menurut Paul Lazarsfeld, model komunikasi dalam teori difusi inovasi adalah komunikasi 
dua tahap yang melibatkan adanya opinion leader atau pemuka pendapat atau disebut juga sebagai agen perubahan (Nurhadi, 2017, p.55).

Rogers (2010, p.5) mendefinisikan difusi sebagai proses inovasi yang dikomunikasikan melalui saluran tertentu dari waktu ke waktu diantara suatu sistem sosial(Rogers, 2010, p.6). Inovasi adalah gagasan, tindakan atau sesuatu yang dianggap baru oleh seseorang dimana kebaruannya itu bersifat relatif (Riva'i, 2016, p.39). "Baru" dalam suatu inovasi bukan berarti pengetahuan yang baru. Jika suatu inovasi telah diketahui oleh seseorang dalam jangka waktu tertentu dan orang tersebut sadar akan hal itu tapi belum memutuskan sikap untuk menyukainya atau tidak, maka hal itu tetap merupakan Inovasi. Jadi, kebaruan inovasi tercermin dari pengetahuan, sikap, ataupun putusan terhadap inovasi tersebut (Rogers, 2010, p.12).

Difusi inovasi yang dikemukakan Roger (1995, p.206 dalam Rosyiana, 2019, p.11) memiliki relevansi dan argumen yang cukup signifikan dalam membuat keputusan inovasi, serta menggambarkan apa yang mempengaruhi tingkat adopsi inovasi dan tahapan dari proses pengambilan keputusan inovasi. Berikut ini beberapa hal yang mempengaruhi tahapan difusi inovasi :

1. Atribut inovasi (perceived attribute of innovasion)

Atribut inovasi merupakan karakteristik inovasi yang telah dipaparkan sebelumnya. Cepat atau lambatnya penerimaan inovasi oleh masyarakat luas dipengaruhi oleh karakteristik inovasi itu sendiri.

2. Jenis keputusan inovasi (type of innovation decisions)

Suatu inovasi dapat diadopsi secara individual ataupun secara otoritas. Secara umum inovasi yang diadopsi oleh individu bersifat opsional, artinya terlepas dari anggota kelompok sosialnya, dan bersifat kolektif mewakili suatu kelompok sosial tertentu melalui sebuah konsensus. Inovasi yang diadopsi secara opsional dapat terjadi lebih cepat dari pada inovasi yang diadopsi secara kolektif. Artinya, semakin banyak orang yang terlibat dalam pembuatan keputusan untuk mengadopsi suatu inovasi maka tingkat adopsi akan semakin lambat. Adopsi inovasi secara otoritas terdapat paksaan dari orang yang mempunyai status yang lebih tinggi dari orang yang membuat keputusan tersebut (Rogers, 2010, p.28-29).

3. Saluran Komunikasi (Communication Channels)

Saluran komunikasi adalah alat untuk menyampaikan pesan-pesan inovasi dari komunikator kepada komunikan. Dua saluran komunikasi menurut Roger
(2010, p.18), yaitu media massa dan komunikasi interpersonal. Jika informasi atau pesan yang hendak disampaikan sudah jelas dan pasti, dan perlu disampaikan kepada khalayak yang banyak dan luas, maka saluran komunikasi yang lebih tepat, cepat dan efisien, adalah media massa. Sementara, saluran komunikasi interpersonal dapat terjadi secara tatap muka dengan pendekatan sosial psikologis.

4. Kondisi Sistem Sosial (Nature of Social System)

Sistem sosial merupakan seperangkat unit yang saling berhubungan satu sama lain dalam tatanan masyarakat sebagai tempat terjadinya difusi. Anggota sistem sosial meliputi individu, tokoh masyarakat, pemimpin formal, atau kelompok tertentu dalam masyarakat secara nyata, baik langsung ataupun tak langsung mempengaruhi proses difusi inovasi. Sistem sosial dapat mengalami perubahan terkait dengan norma, struktur status, pengetahuan, fungsi atau peran, dan sikap yang dimiliki unit dalam sistem sosial tersebut (Rogers, 2010, p.23-24).

5. Peran Agen Perubahan (Agent of change) Agen perubahan adalah orang-orang yang dapat mempengaruhi anggota sistem sosial dimana orang tersebut berada. Peran agen perubahan berkaitan dengan sejauh mana agen perubahan mengupayakan inovasi agar didifusikan. Menurut Roger (2003) dalam Weberg, O'Grady, dan Malloch (2017, p.423-425), ada tujuh peran agen perubahan, diantaranya adalah :

1) Mengembangkan kebutuhan inovasi dan membantu menyadarkan sistem sosial mengenai kebutuhannya akan inovasi tersebut.

2) Membangun kepercayaan dan sebuh pertukaran informasi yang efektif dengan anggota sistem sosial melalui kredibilitas, kompetensi, dan trustworthy.

3) Mendiagnosa permasalahan yang terjadi dalam sistem sosial berkaitan dengan inovasi yang diadakan. Agen perubahan harus mengidentifikasi dan menganalisis penyebab masalah yang terjadi.

4) Menunjukkan dengan jelas bagaimana merealisasikan niat untuk menerima sebuah inovasi kedalam sebuah aksi.

5) Mewujudkan anggota sistem sosial agar mau bertindak dengan memberikan saran yang sesuai melalui komunikasi persuasi interpersonal.

6) Menjaga kestabilan adopsi inovasi anggota sistem sosial dalam kesehariannya dan inovasi telah berkelanjutan melewati tahap 
implementasi ataupun periode evaluasi.

7) Mengakhiri hubungan sistem sosial terhadap agen perubahan merupakan tujuan akhir dari agen perubahan setelah inovasi diadopsi.

Dengan demikian difusi inovasi adalah proses mengkomunikasikan sesuatu yang baru kepada masyarakat tertentu sebagai penyebab perubahan sosial yang terjadi ditengah masyarakat. Proses komunikasi dalam difusi inovasi terus menerus terjadi secara mutlak karena perbedaan setiap individu dalam anggota masyarakat.

\subsection{Perubahan Iklim}

Menurut Ariffin (2003) dalam Ariffin (2019, p.2), iklim adalah rata-rata cuaca di suatu wilayah tertentu yang berlangsung dalam waktu yang panjang, sekurangkurangnya dua puluh lima atau tiga puluh tahun. Unsur-unsur iklim menurut Ariffin (2019, p.3) adalah radiasi matahari, temperature, kelembapan, awan, hujan, evaporasi, tekanan udara, dan angin.

Dalam Undang-Undang No.31 Tahun 2009 tentang Meteorologi, Klimatologi, dan Geofisika, dalam Bab I Pasal 1, perubahan iklim adalah berubahnya iklim yang diakibatkan, langsung, atau tidak langsung, oleh aktivitas manusia yang menyebabkan perubahan komposisi atmosfer secara global serta perubahan variablitias iklim alamiah yang teramati pada kurun waktu yang dapat dibandingkan (Direktorat Utama Pembinaan dan Pengembangan Hukum Pemeriksaan Keuangan Negara BPK RI, 2017b).

\subsection{Sampah}

Menurut Undang - Undang nomor 19 tahun 2008 tentang pengelolaan sampah, dalam Bab I Pasal 1 sampah adalah sisa kegiatan sehari-hari manusia dan/atau proses alam yang berbentuk padat. Berikut ini klasifikasi sampah menurut Suryati (2014, p.3-8) :

1. Berdasarkan bentuknya, ada sampah organik dan an-organik. Sampah organik berupa limbah padat yang mudah terurai secara alami, seperti rumput kering, serbuk gergaji, tangkai sayuran, kulit buah, sisa organisme, dan lain-lain. Sampah an-organik adalah limbah padat yang tidak dapat terurai karena proses alam, seperti botol plastik, logam, kaca, dan lain-lain.

2. Berdasarkan sumbernya, ada limbah padat domestik yang berasal dari rumah sakit, sekolah, perkantoran, dan lain-lain. Serta limbah non-domestik yang biasanya berasal dari hutan, pertanian, perkebunan, dan sebagainya.

3. Berdasarkan tingkat bahaya, ada limbah B3 yang biasanya berisi bahan berbahaya dan beracun seperti limbah dari perindustrian, pertanian, rumah tangga, rumah sakit, dan lain-lain yang dapat berbentuk abses, kamper, pupuk kimia, sterofoam, sampah rumah sakit (bekas infusan, jarum suntik, bekas perban), bekas pembalut wanita, popok bayi, pemutih, deterjen, dan racun tikus. Ada juga limbah non-B3 yang tidak berbahaya bagi kesehatan dan lingkungan, seperti sisa karet penghapus, bolpoin rusak, kaca mata rusak, botol bekas minuman, dan lain-lain.

4. Berdasarkan cara pengelolaan dan pemanfaatannya, ada sampah basah yang terdiri atas bahan organic dan mudah busuk jika dibiarkan basah, seperti sampah rumah tangga, sisa makanan, sayuran, hingga buah-buahan. Ada juga sampah kering yang terdiri dari bahan an-organik dan sebagian besar hampir sulit membusuk.

\subsection{Kesadaran}

"Kesadaran" berasal dari bahasa latin yaitu "concentia" yang artinya "mengerti dengan" dengan kata dasar "sadar" berarti "insyaf, merasa, tau, dan mengerti" (Yuniarto, 2013, p.16).

Kesadaran manusia merupakan unsur penting dalam memahami realitas dan bagaimana menghadapi realitas tersebut (Yuniarto, 2013, p.16-17). "Kesadaran diri" menurut May dalam Koswara (1987, p.31) adalah kapasitas yang memungkinkan manusia mengamati dirinya sendiri maupun membedakan diri dari orang lain, serta kapasitas yang memungkinkan manusia menempatkan diri dalam waktu (Yuniarto, 2013, p.18). Seseorang dengan kesadaran diri mampu menempatkan dirinya sesuai dengan situasi dan kondisi lingkungan, serta dapat belajar dari pengalaman masa lalu untuk bertindak lebih baik dimasa mendatang (Yuniarto, 2013, p.18). Dengan demikian, kesadaran adalah sebuah kondisi dimana seseorang dengan pikiran penuh sadar atas diri dan lingkungannya untuk bertindak dan bersikap.

\subsection{Sosialisasi}

Menurut David A. Goslin dalam Darmawaty \& Djamil (2011, p.69) Sosialisasi adalah proses belajar yang dialami seseorang untuk memperoleh pengetahuan keterampilan, nilai-nilai dan norma-norma agar ia dapat berpartisipasi sebagai anggota kelompok masyarakatnya". Sosialisasi bersifat wajib dan sangat penting, karena semakin anggota sistem sosial itu mengetahui dan memahami apa yang sedang dilakukan oleh organisasi, pemerintah, ataupun perusahaan, maka semakin besar kemungkinan anggota sistem sosial itu mendukung upaya yang akan dan yang sedang dilaksanakan oleh organisasi, 
pemerintah, atau perusahaan tersebut (Hoelman, Parhusip, Eko, Bahagijo, dan Santono, 2016, p.72)

\subsection{Pemuda}

"Pemuda adalah agen perubahan untuk seluruh elemen kehidupan: keluarga, masyarakat, bangsa, dan dunia" (Lestari, 2016, p.1). Pemuda-pemudi merupakan tulang punggung dan agen perubahan menuju hal yang lebih baik, out of the box menjangkau jauh kedepan serta demi keberlanjutan (Hadinagoro, 2019, p.97).

\section{METODOLOGI PENELITIAN}

Penelitian ini menggunakan metode kualitatif deskriptif yang menurut Raco (2010, p.17) cocok untuk meneliti bidang sosial dan kemanusiaan yang terdapat banyak permasalahannya ditengah masyarakat untuk menangkap arti permasalahan sosial dan mempermudah pencarian solusi masalahnya digunakan dalam penelitian ini. Data penelitian yang kemudian dianalisis dengan teknik dari Miles \& Huberman diperoleh melalui studi kepustakaan dan wawancara.

\subsection{Fokus Penelitian}

Tabel 1. Fokus Penelitian

\begin{tabular}{|c|c|c|}
\hline Fokus & Indikator & Evidensi \\
\hline \multirow{5}{*}{$\begin{array}{l}\text { Faktor yang } \\
\text { mempengaruhi difusi } \\
\text { inovasi United Nations } \\
\text { Development } \\
\text { Programme Indonesia } \\
\text { dalam } \\
\text { mengimplementasika } \\
\text { n agenda SDG untuk } \\
\text { membangun } \\
\text { kesadaran pemuda } \\
\text { mengenai masalah } \\
\text { sampah plastik }\end{array}$} & $\begin{array}{l}\text { Atribut inovasi } \\
\text { (perceived } \\
\text { attribute of } \\
\text { innovasion) }\end{array}$ & $\begin{array}{lr}\text { Atribut inovasi } & \text { adalah } \\
\text { karakteristik } & \text { inovasi } \\
\text { yang bersifat } & \text { mutlak } \\
\text { sebagai r pedoman } & \text { masyarakat ralam } \\
\text { memahami situasi dan } \\
\text { permasalahan yang } \\
\text { terjadi di lingkungannya. }\end{array}$ \\
\hline & \begin{tabular}{|l} 
Jenis \\
keputusan \\
inovasi (type of \\
innovation \\
decisions)
\end{tabular} & $\begin{array}{l}\text { Inovasi dapat diadopsi } \\
\text { oleh individual secara } \\
\text { opsional maupun } \\
\text { kolektif dan diadopsi } \\
\text { secara otoritas. }\end{array}$ \\
\hline & $\begin{array}{l}\text { Saluran } \\
\text { komunikasi } \\
\text { (communication } \\
\text { channels) }\end{array}$ & $\begin{array}{l}\text { Saluran komunikasi } \\
\text { merupakan alat untuk } \\
\text { menyampaikan pesan- } \\
\text { pesan inovasi. }\end{array}$ \\
\hline & $\begin{array}{l}\text { Kondisi sistem } \\
\text { sosial (nature } \\
\text { of social } \\
\text { system) }\end{array}$ & $\begin{array}{lr}\text { Sistem } & \text { sosial } \\
\text { merupakan seperangkat } \\
\text { unit yang saling } \\
\text { berhubungan satu sama } \\
\text { lain dalam tatanan } \\
\text { masyarakat sebagai } \\
\text { tempat terjadinya difusi. }\end{array}$ \\
\hline & $\begin{array}{l}\text { Peran agen } \\
\text { perubahan } \\
\text { (agent of } \\
\text { change) }\end{array}$ & $\begin{array}{l}\text { Peran Agen perubahan } \\
\text { adalah sejauh mana } \\
\text { upaya promosi orang- } \\
\text { orang yang dapat } \\
\text { mempengaruhi anggota } \\
\text { sistem sosial dimana } \\
\text { orang tersebut berada. }\end{array}$ \\
\hline
\end{tabular}

Sumber: Rosyiana, 2019; Rogers, 2010

\section{PEMBAHASAN}

Sampah adalah material sisa yang tidak diinginkan setelah berakhirnya suatu proses. Indonesia adalah penghasil sampah plastik terbesar kedua di dunia. Untuk mengatasi masalah sampah plastik, Indonesia sebagai anggota PBB, dalam organisasi UNDP mengupayakan tujuan pembangunan yang terdapat dalam agenda SDG ini. Masalah sampah plastik yang menyebabkan perubahan iklim sudah menjadi tujuan determinan UNDP yang bisa diimplementasikan melalui difusi inovasi agenda SDG dan ditunjukkan kepada golongan pemuda.

Komunikasi pembangunan telah dilaksanakan UNDP Indonesia melalui berbagai saluran komunikasi, yaitu internet dengan menggunakan website, sosial media, dan email untuk menyebarkan informasi kegiatan yang diadakannya. Serta mengkomunikasikan inovasi kepada partisipan dan pihak-pihak lain yang terlibat dalam event/program UNDP secara langsung maupun tidak langsung bersama agen-agen perubahan, dan juga lobbying untuk kerjasama dengan pemerintah dalam merancang penetapan regulasi mengenai penggunaan plastik.

Hasil penelitian dalam Jenis keputusan Inovasi diharapkan pada individu daldan kelompok golongan pemuda untuk berperilaku mengurangi penggunaan plastik sekali pakai dan menjadi kritis terhadap segala hal yang tidak ramah lingkungan. Inovasi untuk individu diharapkan dapat diadopsi secara kolektif, kemudian UNDP Indonesia mengharapkan gerakan masif pemuda dalam skala nasional untuk mengatasi masalah sampah plastik.

Hasil penelitian menunjukkan Tim Komunikasi UNDP Indonesia saat ini telah berfokus pada penyebaran informasi yang dikemas secara ramah untuk kalangan pemuda. Namun, membangun kesadaran merupakan hal yang bersifat jangka panjang, dan sulit diukur bagi UNDP Indonesia, sehingga saat ini UNDP Indonesia hanya melihat keaktifan partisipasi dan respon peserta kegiatan sosialisasi SDG yang diadakannya. UNDP Indonesia tidak melakukan evaluasi kegiatan komunikasinya, dan belum bisa mengukur keberhasilan kegiatannya. UNDP Indonesia melihat keberhasilan saat ada perubahan kebijakan yang menjadi sesuai dengan inovasi yang diharapkan. Dalam menghadapi masalah sampah plasitk, Environment Unit di UNDP Indonesia juga hanya mengupayakan penanganan masalah sampah plastik melalui program perlindungan Biodiversity yang tidak difokuskan targetnya kepada pemuda.

UNDP Indonesia telah melibatkan peran agen perubahan dalam implementasi difusi inovasi agenda SDG. Hasil penelitian menunjukkan agen perubahan bagi UNDP Indonesia bisa merupakan orang yang sudah 
berkomitmen pada kehidupan yang sesuai SDG, bisa juga orang yang belum memahami apa itu SDG, namun orang tersebut memiliki banyak followers/pengikut dibidangnya. Selain itu, riwayat hidup yang meliputi keaktifan di sosial media, keaktifan kegiatan dibidangnya, kesesuaian produk atau karya yang dihasilkannya dengan agenda SDG, keterlibatan terhadap obatobat terlarang, kontroversi yang pernah dialami, prestasi yang diraih, dan lain-lain juga menjadi kriteria agen perubahan bagi UNDP Indonesia.

Agen perubahan ini bisa merupakan anggota dari sebuah komunitas, seorang pemimpin, tokoh sosial, influencer, public figure, pihak pemerintahan, pemangku kepentingan dalam corporate, pengusaha. UNDP Indonesia juga tidak menutup kemungkinan untuk agen-agen perubahan berasal dari pihak internalnya. UNDP Indonesia juga mengharapkan agar agenagen perubahan yang dilibatkannya tidak hanya aktif dalam mengimplementasikan SDG, tetapi juga aktif berpartisipasi dalam kegiatan yang diadakan UNDP Indonesia.

UNDP Indonesia membekali para agen perubahan yang belum memahami aspekaspek SDG dengan pengetahuan, melalui dialog yang diarahkan pada berbagai peluang kesepakatan kerjasama. Saat ini UNDP sudah memiliki agen perubahan resmi yang disebut "SDG Mover" yang bersifat voluntary. Namun, dalam menyertakan agen perubahan ini, hasil penelitian menunjukkan adanya kendala, yaitu belum begitu menariknya isu SDG ditengah masyarakat. Selain itu, banyaknya Tujuan Pembangunan Berkelanjutan yang sejumlah 17 membuat UNDP Indonesia sulit memilih fokus dalam setiap kegiatanya untuk mengimplementasikan difusi inovasi agenda SDG.

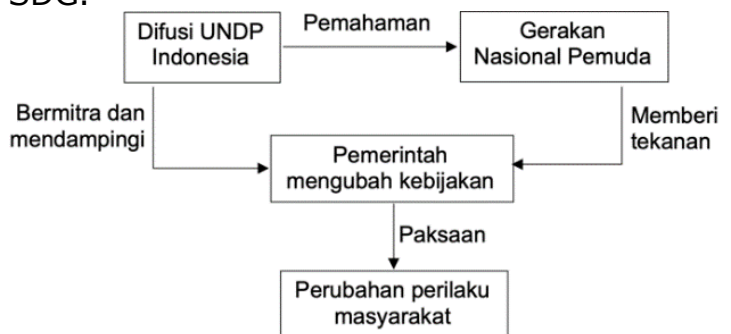

Gambar 2 Proses Perubahan Perilaku Masyarakat

Padahal atribut inovasi yang ditemukan dalam penelitian ini, keuntungan relatif terdapat pada inovasi yang diharapkan untuk membangun kesadaran pemuda, karena dalam skala nasional, gerakan dari pemuda dapat mendorong atau mempercepat pemerintah memberlakukan kebijakan terkait masalah sampah plastik. Kebijakan/regulasi bersifat mengikat dan memaksa sehingga dapat mengubah gaya hidup masyarakat Indonesia menjadi sesuai dengan nilai-nilai SDG terhadap lingkungan. Gaya hidup terhadap lingkungan yang perlu diubah lah yang menjadi kerumitan untuk mencapai adopsi inovasi. Kondisi masyarakat saat ini yang tidak menaruh harapan pada pemerintah bisa menjadi penyebab gerakan masif nasional yang diharapkan pada pemuda masih belum ada.

Mengenai kondisi sistem sosial di Indonesia hasil penelitian menunjukkan, Masyarakat mempunyai gaya hidup yang buruk bagi lingkungan. Hal ini sulit diperbaiki karena saat ini Indonesia terperangkap dalam kategori negara berpenghasilan menengah, dan masalah sampah plastik adalah salah satu komponen determinan yang menentukan Indonesia bisa naik kelas atau tidak. Hasil penelitian menunjukkan bahwa kesadaran lingkungan sudah terbangun dikalangan pemuda yang berusia dua puluh lima tahun kebawah dengan karakter pemuda yang bersedia menjadi ruwet dalam mengubah gaya hidupnya. Namun, kuantitas kelompok masyarakat ini masih belum signifikan untuk populasi yang ada.

\section{KESIMPULAN DAN SARAN}

\subsection{Kesimpulan}

Dari penelitian mengenai Peran UNDP Indonesia dalam Mengimplementasikan Difusi Inovasi Agenda SDG untuk Membangun Kesadaran Pemuda Mengenai Masalah Sampah Plastik yang telah dilakukan, didapatkan kesimpulan sebagai berikut:

1. Inovasi yang perlu diadopsi untuk mengimplementasikan difusi agenda SDG mengenai masalah sampah plastik tidak begitu sulit karena sudah ada kesadaran pemuda yang terbangun, dan hanya memerlukan difusi dengan pendekatan langsung yang ramah dan mudah dipahami kaum pemuda.

2. UNDP Indonesia mengharapkan inovasi agar diadopsi oleh setiap individu dan kelompok pemuda Indonesia yang berupa perubahan pada pola pikir, perilaku, dan gaya hidup.

3. Difusi inovasi agenda SDG mengenai masalah sampah plastik dilakukan UNDP Indonesia melalui internet, event atau program, dan lobbying dengan melibatkan influencer yang dapat mempengaruhi pemuda.

4. Kemajemukan Indonesia menciptakan berbagai situasi dan kondisi yang positif dan negatif terhadap isu sampah plastik. Semua yang telah dilaksanakan UNDP Indonesia masih belum signifikan untuk menciptakan perubahan yang lebih baik dalam mengatasi masalah sampah plastik. 
5. Kriteria agen perubahan UNDP Indonesia telah sesuai dengan nilai-nilai pembangunan berkelanjutan, dan UNDP Indonesia telah melibatkan agen perubahan dalam difusi inovasi yang dilakukannya, meski masih mengalami kesulitan.

\subsection{SARAN}

UNDP Indonesia sebaiknya fokus pada apa saja yang dapat dilakukannya untuk menciptakan perubahan lingkungan yang lebih signifikan. Environment Unit di UNDP Indonesia juga sebaiknya mengadakan beberapa kegiatan yang diarahkan pada pemuda Indonesia mengenai masalah sampah plastik. Evaluasi setiap kegiatan yang dilaksanakan UNDP Indonesia juga perlu dilakukan untuk mengembangkan kegiatan-kegiatan yang akan diadakan selanjutnya.

Masyarakat Indonesia khususnya kalangan pemuda yang tertarik dengan isu lingkungan sebaiknya mulai aktif bergerak mulai dengan mendukung dan berpartisipasi dalam kegiatan-kegiatan terkait penanganan masalah lingkungan hingga menerapkan dan mempertahankan gaya hidup yang ramah lingkungan dengan sungguh-sungguh, bukan hanya sebagai gimmick semata.

\section{DAFTAR PUSTAKA}

[1] Ariffin. (2019). Metode Klasifikasi Iklim di Indonesia. Malang, Indonesia: UB Press.

[2] Ardial. (2018). Komunikasi Organisasi. Medan, Indonesia: Lembaga Penelitian dan Penulisan IImiah AQLI.

[3] Darmawaty, Y., \& Djamil, A. (2011). Buku Saku Sosiologi SMA. Jakarta, Indonesia: PT Kawan Pustaka

[4] [4] Hadinagoro, K. S. S. (2019). Perkokoh Ke-Indonesia-an Kita. Yogyakarta, Indonesia: Deepublish.

[5] Harun, H., R. \& Ardianto, E. (2011). Komunikasi Pembangunan dan Perubahan Sosial Perspektif Dominan, Kaji Ulang, dan Teori Kritis. Depok, Indonesia: PT Rajagrafindo Persada.

[6] Hoelman, M., B. Parhusip, B., T., P. Eko, S. Bahagijo, S. dan Santono, H. (2016). Sustainable Development Goals-SDGs. Jakarta, Indonesia: infid.

[7] Incognito, T. (2015). Jejak-Jejak di Tanah Antah-Berantah. Yogyakarta, Indonesia: Garudhawaca.

[8] Komandoko, G. (2010). Ensiklopedi Pelajar dan Umum. Yogyakarta, Indonesia: Pustaka Widyatama.

[9] [9]Kriyantono, R. (2019). Pengantar Lengkap Ilmu Komunikasi Filsafat dan Etika Ilmunya Serta Perspekfif Islam. Jakarta, Indonesia: Kencana.
[10] Lestari, A. (2016). Menjadi Pemuda Harapan Bangsa. Jakarta, Indonesia: PT Elex Media Komputindo.

[11] Oktarina, Y., \& Abdullah, Y. (2017). Komunikasi dalam Perspektif Teori dan Praktik. Yogyakarta, Indonesia: Deepublish.

[12] Pusat Data dan Analisis Tempo. (2019). Diplomasi Indonesia di PBB. Jakarta, Indonesia: Tempo Publishing. Diperoleh dari:

https://books.google.co.id/books?id=Il UDWAAQBAJ\&dq=(2019). +Diplomasi+I ndonesia+di+PBB.+++tempo\&source= gbs_navlinks_s

[13] Raco, J. R. (2010). Metode Penelitian Kualitatif. Jakarta, Indonesia: Grasindo.

[14] Riva'i, A., K. (2016). Komunikasi Sosial Pembangunan. Pekan Baru, Indonesia: Hawa dan AHWA.

[15] Rogers, E., M. (2010). Diffusion of Innovations, 4th Edition. New York, Amerika Serikat: Simon \& Schuster.

[16] Rosyiana, I., S., M. (2019). Innovative Bheavior At Work. Yogyakarta, Indonesia: Deepublish.

[17] Sari, A., A. (2017). Dasar-Dasar Public Relations Teori dan Praktik. Yogyakarta, Indonesia: Deepublish.

[18] Suryati, T. (2014). Bebas Sampah Dari Rumah. Jakarta, Indonesia: PT AgroMedia Nusantara.

[19] Umbara, R., P. (2018). Panduan Resmi Tes BUMN CAT / PBT. Jakarta, Indonesia: PT Bintang Wahyu.

[20] Weberg, D. O'Grady, T., P. dan Malloch, K. (2017). Leadership for EvidenceBased Innovation in Nursing and Health Professions. Burlington, Amerika Serikat: Jones \& Bartlett Learning

[21] Yuniarto, B. (2013). Membangun Kesadaran Warga Negara Dalam Pelestarian Lingkungan. Yogyakarta, Indonesia: Deepublish

[22] Fatah, D. (2019 Juli, 7). Wow, Indonesia Produksi 64 Juta Ton Sampah per Tahun. Diperoleh dari: https://indopos.co.id/read/2019/07/07/ 180601/wow-indonesia-produksi-64juta-ton-sampah-per-tahun/

[23] Pramudyani, Y. D. (2019 Maret, 30). Jokowi: Indonesia Harus Tegak Jalankan Politik Luar Negeri Bebas Aktif. Diambil dari: https://pemilu.antaranews.com/berita/8 17928/jokowi-indonesia-harus-tegakjalankan-politik-luar-negeri-bebas-aktif

[24] Commonwealth Secretariat. (2016). Global Youth Development Index and Report. Diambil dari: https://books.google.co.id/books?id=NP F-DQAAQBAJ\&printsec $=$ frontcover

[25] Fitri, S. P. (2016, Oktober). SDG 2030 Indonesia. Diambil dari: https://www.sdg2030indonesia.org/ancomponent/media/upload- 
book/Briefing_paper_No_1_SDGS_2016-Meila_Sekar.pdf

[26] Maylasari, I. Rachmawati, Y. Agustina, R. Silviliyana, M. Dewi, F., W., R. Annisa, L. Lanny, T \& Nugroho, S., W. (2018). Statistik Pemuda Indonesia. Jakarta: Badan pusat Statistik. Diambil dari:

https://www.bps.go.id/publication/2018 /12/21/572f941511d090083dd742d6/st atistik-pemuda-indonesia-2018.html

[27] Direktorat Jenderal Pengendalian Perubahan Iklim. (2017). Ubah Kebiasaan Penggunaan Plastik. Diambil dari:

http://ditjenppi.menlhk.go.id/kcpi/index .php/inovasi/347-ubah-kebiasaanpenggunaan-plastik

[28] Direktorat Utama Pembinaan dan Pengembangan Hukum Pemeriksaan Keuangan Negara BPK RI. (2017a). Undang-undang (UU) No. 30 Tahun 2019 Perjanjian Internasional. Diambil dari:

https://peraturan.bpk.go.id/Home/Detai Is/110255/perpres-no-30-tahun-2019

[29] Direktorat Utama Pembinaan dan Pengembangan Hukum Pemeriksaan Keuangan Negara BPK RI. (2017b). Undang-undang (UU) No. 31 Tahun 2009 Perjanjian Internasional. Diambil dari:

https://peraturan.bpk.go.id/Home/Detai Is/38769/uu-no-31-tahun-2009

[30] UNDP Asia Pacific. (2019c). SDG: UNDP Asia Pacific. Diambil dari: https://www.asia-

pacific.undp.org/content/rbap/en/home/ sustainable-development-goals.html

[31] UNDP Indonesia. (n.d.-a). Home: United Nations Development Programme Indonesia. Diambil dari: https://www.id.undp.org

[32] UNDP Indonesia. (n.d.-b). UNDP Indonesia: Kemitraan untuk Tujuan Pembangunan Berkelanjutan. Diambil dari:

https://www.google.com/url?sa $=$ t\&rct $=j$ $\& q=\& e s r c=s \&$ source $=$ web $\& c d=1 \&$ ved $=$ 2ahUKEwjk95eu4aDIAhVDu48KHZO_AG YQFjAAegQIBBAC\&url=http $\% 3 A \% 2 \bar{F} \% 2$ Fwww.id.undp.org\%2Fcontent\%2Fdam $\% 2$ Findonesia\%2F2016\%2Fpressdoc\%2FUNDP\%2520Indonesia\%2520Pa rtnerships\%2520for\%2520the\%2520SD $\mathrm{G}$ 